\title{
The Optimum Study on Mechanical Properties of Self-drilling Tapping Screws with Carbonitriding Operation
}

\author{
Chih-Cheng Yang", His-Cheng Liu \\ Department of Mechanical and Automation Engineering, Kao Yuan University, Taiwan
}

Copyright $(2017$ by authors, all rights reserved. Authors agree that this article remains permanently open access under the terms of the Creative Commons Attribution License 4.0 International License

\begin{abstract}
Self-drilling tapping screws are widely used for construction works. In order to increase the strength and improve the wear resistance without affecting the soft, tough interior of the screws in self-drilling operation, a case-hardening treatment is an essential process. Carbonitriding primarily provides a needed hard, wear-resistant case of screws. In order to improve the qualities of AISI 1016 self-drilling tapping screws, a series of carbonitriding experiment is conducted in a continuous furnace. Various parameters affect the quality of carbonitriding such as quenching temperature, carbonitriding time, atmosphere composition and tempering temperature. The effects of carbonitriding parameters affected the quality characteristics, such as case hardness and core hardness of self-drilling tapping screws are analyzed by Taguchi method. It is experimentally revealed that the carbonitriding time and tempering temperature are the significant factors for both case hardness and core hardness. The optimum mean case hardness is $625.5 \mathrm{HV}$, and the optimum mean core hardness is $368.7 \mathrm{HV}$. With the optimum conditions, the carbonitriding treatment is capable of producing good self-drilling tapping screws. The results presented in this paper could be used as a reference for fastener manufacturers.
\end{abstract}

Keywords Self-drilling Tapping Screw, Carbonitriding, Taguchi Method, Case Hardness, Core Hardness

\section{Introduction}

Self-drilling tapping screws, as shown in Figure 1, are widely used for construction works. The manufacturing processes of fasteners generally include wire-manufacturing, forming, heat treating, coating, and packing. In order to readily fabricate into tapping screws, low-carbon steel wires are usually used. To increase the strength of screws in self-drilling operation, a case-hardening treatment is usually an essential process. Case hardening is used to improve the wear resistance of parts without affecting the soft, tough interior of the screws. This combination of hard surface and resistance to breakage is useful in self-drilling tapping screws that must have a very hard surface to resist wear, along with a tough interior to resist the breakage that occurs during operation.

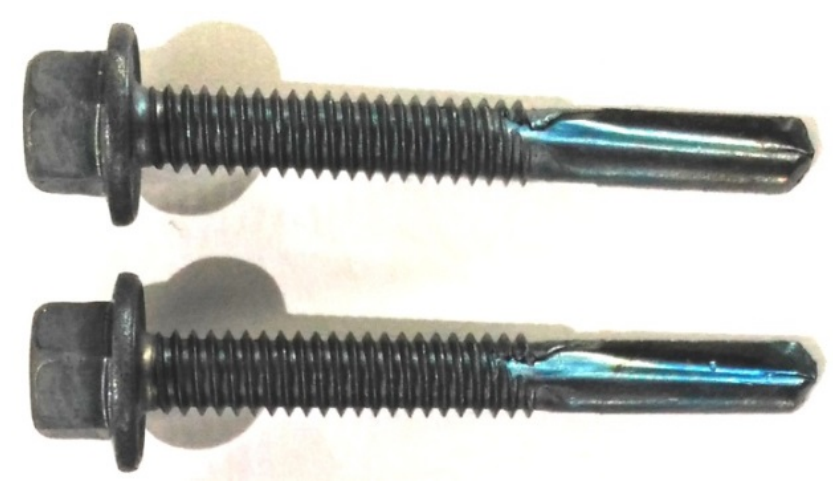

Figure 1. Self-drilling tapping screws $(\mathrm{M} 5.5 \times 40 \mathrm{~mm})$

Gas carburizing is a case-hardening process in which carbon is dissolved in the surface layers of a low-carbon steel part at a temperature sufficient to render the steel austenitic, followed by quenching and tempering to form a martensitic microstructure [1]. The successful operation of the gas carburizing process depends on the control of various principal variables, such as temperature, time and atmosphere composition. Steel for carburizing is usually a low-carbon steel of about $0.15 \%$ carbon that would not respond appreciably to heat treatment. The process converts the outer layer into a high-carbon steel, with a content ranging from $0.9 \%$ to $1.2 \%$ carbon [2].

Carbonitriding is a modified form of gas carburizing. The reactions occurring during the carbonitriding process have been studied theoretically and experimentally [3]. Carbonitriding process by diffusing of both carbon and 
nitrogen into the surface layer enables the process to be carried out at lower temperatures and a shorter time than with carbon alone. Carbonitriding is used primarily to impart a hard, wear-resistant case, generally from 0.075 to $0.75 \mathrm{~mm}$ deep. The depth of the case depends on the time and temperature of treatment. A carbonitriding case has better hardenability than a carburized case since nitrogen increases the hardenability of steel [4]. Carbonitriding is an excellent choice for low carbon fastener materials that require a uniform, but shallow case with good wear properties [5]. The combined diffusion profile of carbon and nitrogen applied in a carbonitriding process plays a major role, besides the process temperature. Winter [6] presented a new system able to measure and control both the carbon potential and the nitrogen potential independently.

In order to improve the qualities of self-drilling tapping screws, a series of carbonitriding experiment is conducted in a continuous furnace. Various parameters affect the quality of carbonitriding such as quenching temperature, carbonitriding time, atmosphere composition (carbon potential and ammonia level), and tempering temperature. The effects of carbonitriding parameters affected the quality characteristics, such as case hardness and core hardness of AISI 1016 self-drilling tapping screws are analyzed by Taguchi method $[7,8]$ in this study.

\section{Experiment Design}

AISI 1016 self-drilling tapping screws are investigated in this study. A series of carbonitriding experiment is conducted in a continuous furnace which schematic is given in Figure 2. Carburizing and carbonitriding are often used together to achieve much deeper case depths and better engineering performance for self-drilling tapping screws [4]. In the furnace, zone 1 is for preheating; zones 2 and 3 are mainly for carburizing by adding propane $\left(\mathrm{C}_{3} \mathrm{H}_{8}\right)$ at higher operating temperature of $870 \sim 880^{\circ} \mathrm{C}$ to give the desired total case depth; zones 4 and 5 are for carbonitriding by adding propane $\left(\mathrm{C}_{3} \mathrm{H}_{8}\right)$ and ammonia $\left(\mathrm{NH}_{3}\right)$ in the lower temperature range of 840 to $870^{\circ} \mathrm{C}$ to add the desired carbonitrided case depth; zone 6 is for quenching at lower operating temperature of $800 \sim 840^{\circ} \mathrm{C}$; and then, the screws are oil quenched, followed by tempering in the temperature range of 300 to $340^{\circ} \mathrm{C}$.

In order to evaluate the mechanical properties of the self-drilling tapping screws, eight controllable process factors are identified: 1 at two levels and 7 at three levels. All factors and their levels are shown in Table 1.

Taguchi method allows the changing of many factors at the same time in a systematic way, ensuring the reliable and independent study of the factors' effects. The orthogonal array table, $\mathrm{L}_{18}\left(2^{1} \times 3^{7}\right)$, is used as an experimental design for these eight factors $[7,8]$, as listed in Table 2 .

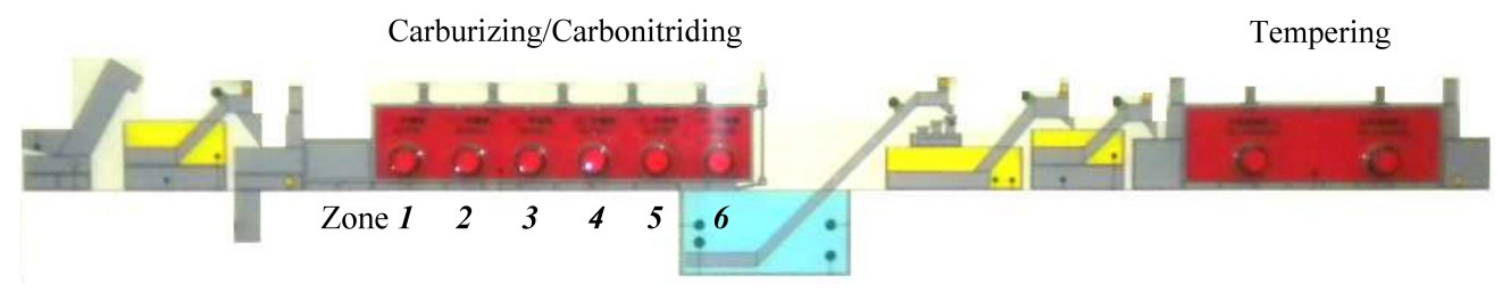

Figure 2. The schematic illustration of a continuous furnace

Table 1. Experimental factors and their levels for $\mathrm{L}_{18}$ orthogonal array

\begin{tabular}{|c|c|c|c|}
\hline Factor & Level 1 & Level 2 & Level 3 \\
\hline A: Temperature of zone $3\left({ }^{\circ} \mathrm{C}\right)$ & 870 & 880 & \\
\hline B: Temperature of zone $5\left({ }^{\circ} \mathrm{C}\right)$ & 840 & 850 & 870 \\
\hline C: Temperature of zone $6\left({ }^{\circ} \mathrm{C}\right)$ & 800 & 820 & 840 \\
\hline D: Carbonitriding time (min) & 40 & 50 & 60 \\
\hline E: Carbon potential (\%) & 1.0 & 0.9 & 0.8 \\
\hline F: Flow rate of ammonia $\left(\mathrm{NH}_{3}\right)(l / \mathrm{min})$ & 0.6 & 0.5 & 0.4 \\
\hline G: Tempering temperature $\left({ }^{\circ} \mathrm{C}\right)$ & 300 & 320 & 340 \\
\hline H: Tempering time (min) & 40 & 45 & 50 \\
\hline
\end{tabular}


Table 2. $\mathrm{L}_{18}\left(2^{1} \times 3^{7}\right)$ orthogonal array experimental parameter assignment.

\begin{tabular}{|c|c|c|c|c|c|c|c|c|}
\hline $\begin{array}{l}\text { Exp. } \\
\text { No. }\end{array}$ & $\begin{array}{c}\text { A: } \\
\text { Temperature of } \\
\text { zone } 3 \\
\left({ }^{\circ} \mathrm{C}\right)\end{array}$ & $\begin{array}{c}\text { B: } \\
\text { Temperature of } \\
\text { zone } 5 \\
\left({ }^{\circ} \mathrm{C}\right)\end{array}$ & $\begin{array}{c}\text { C: } \\
\text { Temperature of } \\
\text { zone } 6 \\
\left({ }^{\circ} \mathrm{C}\right) \\
\end{array}$ & $\begin{array}{c}\mathrm{D}: \\
\text { Carbonitriding } \\
\text { time } \\
(\mathrm{min})\end{array}$ & $\begin{array}{c}\text { E: } \\
\text { Carbon } \\
\text { potential } \\
(\%) \\
\end{array}$ & $\begin{array}{c}\text { F: } \\
\text { Flow rate of } \\
\text { ammonia } \\
(\mathrm{l} / \mathrm{min})\end{array}$ & $\begin{array}{c}\mathrm{G}: \\
\text { Tempering } \\
\text { temperature } \\
\left({ }^{\circ} \mathrm{C}\right)\end{array}$ & $\begin{array}{c}\mathrm{H}: \\
\text { Tempering } \\
\text { time } \\
(\mathrm{min})\end{array}$ \\
\hline$L 1$ & 870 & 840 & 800 & 40 & 1.0 & 0.6 & 300 & 40 \\
\hline$L 2$ & 870 & 840 & 820 & 50 & 0.9 & 0.5 & 320 & 45 \\
\hline$L 3$ & 870 & 840 & 840 & 60 & 0.8 & 0.4 & 340 & 50 \\
\hline L4 & 870 & 850 & 800 & 40 & 0.9 & 0.5 & 340 & 50 \\
\hline$L 5$ & 870 & 850 & 820 & 50 & 0.8 & 0.4 & 300 & 40 \\
\hline L6 & 870 & 850 & 840 & 60 & 1.0 & 0.6 & 320 & 45 \\
\hline$L 7$ & 870 & 870 & 800 & 50 & 1.0 & 0.4 & 320 & 50 \\
\hline$L 8$ & 870 & 870 & 820 & 60 & 0.9 & 0.6 & 340 & 40 \\
\hline$L 9$ & 870 & 870 & 840 & 40 & 0.8 & 0.5 & 300 & 45 \\
\hline$L 10$ & 880 & 840 & 800 & 60 & 0.8 & 0.5 & 320 & 40 \\
\hline$L 11$ & 880 & 840 & 820 & 40 & 1.0 & 0.4 & 340 & 45 \\
\hline$L 12$ & 880 & 840 & 840 & 50 & 0.9 & 0.6 & 300 & 50 \\
\hline$L 13$ & 880 & 850 & 800 & 50 & 0.8 & 0.6 & 340 & 45 \\
\hline$L 14$ & 880 & 850 & 820 & 60 & 1.0 & 0.5 & 300 & 50 \\
\hline$L 15$ & 880 & 850 & 840 & 40 & 0.9 & 0.4 & 320 & 40 \\
\hline$L 16$ & 880 & 870 & 800 & 60 & 0.9 & 0.4 & 300 & 45 \\
\hline$L 17$ & 880 & 870 & 820 & 40 & 0.8 & 0.6 & 320 & 50 \\
\hline$L 18$ & 880 & 870 & 840 & 50 & 1.0 & 0.5 & 340 & 40 \\
\hline
\end{tabular}

Case hardness

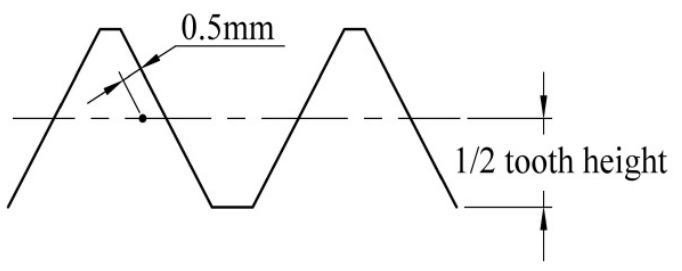

$1 / 2$ basic minor diameter

Centerline of screw thread

(a)

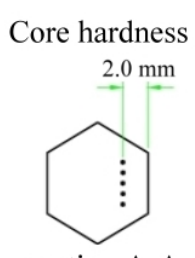

section A-A

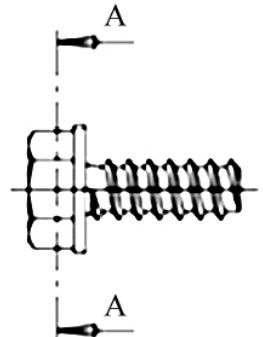

(b)

Figure 3. The schematic illustration of measuring: (a) case hardness, (b) core hardness.

In this study, two quality characteristics of the carbonitriding self-drilling tapping screws, case hardness and core hardness as measured in Figure 3, are investigated. Each test trial, including 9 specimens, is followed by each fabrication process and the results are then transformed to the $\mathrm{S} / \mathrm{N}$ ratio (signal-to-noise ratio). For a non-treating screw, the case hardness of $173.3 \mathrm{HV}$ is measured on the tooth (Figure 3a) and the core hardness of $253.6 \mathrm{HV}$ is tested in the head (Figure 3b). Since the hardness of workpiece may be increased by plastic flow [9], the core hardness is greater than the case hardness mainly due to heavier plastic work in heading than in threading.

Carbonitriding primarily provides a needed hard, wear-resistant case of screws. Through carbonitriding, the strength of self-drilling tapping screws may be improved, and the case hardness, which is the main quality characteristic and is obtained from the Vickers hardness test, may be increased as well. Therefore, the case hardness of the self-drilling tapping screws should be exceeding $590 \mathrm{HV}$, which is assigned by the company. Therefore, in terms of the desired characteristics for the case hardness, the greater the better, and the $\mathrm{S} / \mathrm{N}$ ratio is [8]

$$
\mathrm{S} / \mathrm{N}=-10 \log \frac{\sum_{i=1}^{n} 1 / y_{i}^{2}}{n},
$$


where $y_{i}$ is the case hardness and $n$ is the test number of each trial.

Case hardening is used to improve the wear resistance of screws without affecting the soft, tough interior of the screws; and is useful in self-drilling tapping screws that have a very hard surface to resist wear, along with a tough interior to resist the breakage that occurs during operation. As assigned by the company, the core hardness of the self-drilling tapping screws should be between 240 and $400 \mathrm{HV}$. Therefore, in terms of the desired characteristics for the core hardness, the smaller the better, and the $\mathrm{S} / \mathrm{N}$ ratio is [8]

$$
\mathrm{S} / \mathrm{N}=-10 \log \frac{\sum_{i=1}^{n} y_{i}^{2}}{n},
$$

where $y_{i}$ is the core hardness and $n$ is the test number of each trial.

Analysis of variance (ANOVA) is an effective method to determine the significant factors and the optimal fabrication conditions to obtain optimal quality. For Taguchi method, the experimental error is evaluated with ANOVA to carry out the significance test of the various factors. The nature of the interaction between factors is considered as experimental error [8]. If the effect of a factor in comparison to the experimental error is sufficiently large, it is identified as a significant factor. The confidence level of a factor is evaluated with the experimental error to identify the significant factor that influences the material property of the self-drilling tapping screws.

\section{Results and Discussion}

The microstructure of self-drilling tapping screw is shown in Figure 4a. This is not treated yet. Carbonitriding is the process of diffusing both carbon and nitrogen into the surface layer, as shown in Figure 4b, to impart a hard, wear-resistant case. Compared with the measures of non-treated screws, the core hardness and case hardness are increased together, while the increment of case hardness (more than $400 \mathrm{HV}$ ) is much more than core hardness (less than 100HV).

The experimental results of the core hardness and case hardness (mean, $\mu$; standard deviation, $S$; and $\mathrm{S} / \mathrm{N}$ ratio) of the carbonitrided self-drilling tapping screws are shown in Table 3. The mean case hardness varies from 577.7 to $643.7 \mathrm{HV}$, and the mean values of tests L4 L6, L11, L13, L15 and L17 are not exceeding 590HV, as shown in Table 3. The standard deviation of test L3 is the smallest of the eighteen tests. As shown in Table 3, the mean core hardness varies from 309.7 to $349.6 \mathrm{HV}$, and the standard deviation of test L13 is the smallest of the eighteen tests. The properties of carbonitrided self-drilling tapping screws are obviously altered with various carbonitriding process conditions.

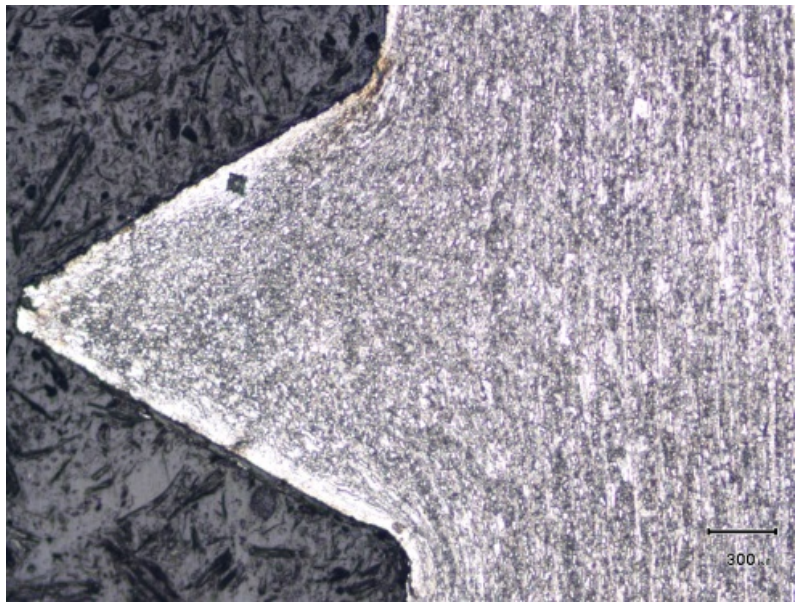

(a)

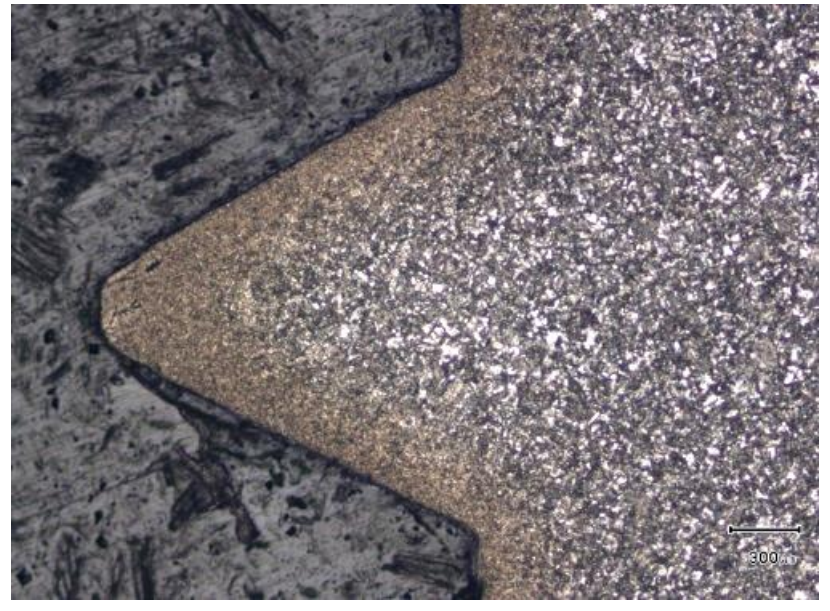

(b)

Figure 4. Microstructures of tapping screw $(\times 200)$. (a) Non-treated; (b) Carbonitrided. 
Table 3. The experimental results for case hardness and core hardness

\begin{tabular}{|c|c|c|c|c|c|c|}
\hline \multirow{2}{*}{$\begin{array}{l}\text { Exp. } \\
\text { No. }\end{array}$} & \multicolumn{3}{|c|}{ Case hardness } & \multicolumn{3}{|c|}{ Core hardness } \\
\hline & $\mu(\mathrm{HV})$ & $S$ & $\mathrm{~S} / \mathrm{N}$ ratio & $\mu(\mathrm{HV})$ & $S$ & $\mathrm{~S} / \mathrm{N}$ ratio \\
\hline$L 1$ & 595.8 & 12.65 & 55.50 & 312.2 & 10.00 & -49.89 \\
\hline$L 2$ & 610.1 & 13.02 & 55.70 & 318.8 & 15.67 & -50.08 \\
\hline$L 3$ & 595.6 & 4.80 & 55.50 & 324.3 & 12.44 & -50.23 \\
\hline$L 4$ & 570.7 & 9.50 & 55.12 & 309.7 & 12.76 & -49.82 \\
\hline$L 5$ & 586.4 & 13.19 & 55.36 & 338.4 & 16.56 & -50.60 \\
\hline L6 & 588.3 & 10.70 & 55.39 & 329.6 & 12.46 & -50.36 \\
\hline$L 7$ & 608.2 & 14.14 & 55.68 & 337.9 & 13.68 & -50.58 \\
\hline$L 8$ & 591.9 & 11.45 & 55.44 & 319.2 & 10.26 & -50.09 \\
\hline$L 9$ & 605.1 & 11.23 & 55.63 & 333.0 & 10.98 & -50.45 \\
\hline$L 10$ & 598.7 & 11.12 & 55.54 & 338.7 & 16.92 & -50.61 \\
\hline$L 11$ & 564.3 & 8.00 & 55.03 & 316.9 & 13.62 & -50.03 \\
\hline$L 12$ & 618.4 & 14.52 & 55.82 & 315.8 & 13.09 & -49.99 \\
\hline$L 13$ & 587.6 & 7.55 & 55.38 & 329.9 & 7.20 & -50.37 \\
\hline$L 14$ & 621.6 & 18.45 & 55.86 & 328.3 & 13.39 & -50.33 \\
\hline$L 15$ & 587.7 & 8.53 & 55.38 & 326.2 & 9.27 & -50.27 \\
\hline$L 16$ & 643.7 & 13.58 & 56.17 & 349.6 & 7.86 & -50.87 \\
\hline$L 17$ & 577.7 & 11.83 & 55.23 & 325.7 & 14.89 & -50.26 \\
\hline$L 18$ & 590.0 & 8.19 & 55.41 & 319.6 & 15.12 & -50.10 \\
\hline Ave & 596.8 & 11.25 & 55.51 & 326.3 & 12.56 & -50.27 \\
\hline
\end{tabular}

* Experimental conditions as defined in Table 2.

Table 4. Variance analysis table of signal-to-noise $(\mathrm{S} / \mathrm{N})$ ratio for case hardness

\begin{tabular}{|c|c|c|c|c|}
\hline Factor & SS & DOF & Var & Contribution \\
\hline A & 0.014 & 1 & 0.014 & $1.09 \%$ \\
\hline B & 0.096 & 2 & 0.048 & $3.50 \%$ \\
\hline C & 0.051 & 2 & 0.025 & $28.01 \%$ \\
\hline D & 0.357 & 2 & 0.179 & $7.17 \%$ \\
\hline E & 0.092 & 2 & 0.046 & $1.85 \%$ \\
\hline F & 0.024 & 2 & 0.012 & $39.49 \%$ \\
\hline G & 0.504 & 2 & 0.252 & $3.42 \%$ \\
\hline H & 0.044 & 2 & 0.022 & $7.49 \%$ \\
\hline others & 0.096 & 17 & 0.048 & $100.00 \%$ \\
\hline Total & 1.276 & & \\
\hline
\end{tabular}

\begin{tabular}{|c|c|c|c|c|c|c|}
\hline \multicolumn{7}{|c|}{ Pooling of errors } \\
\hline Factor & $S S$ & DOF & Var & $\mathrm{F}$ & Confidence & Significance \\
\hline A & \multicolumn{6}{|c|}{ Pooled } \\
\hline B & \multicolumn{6}{|c|}{ Pooled } \\
\hline $\mathrm{C}$ & \multicolumn{6}{|c|}{ Pooled } \\
\hline $\mathrm{D}$ & 0.357 & 2 & 0.179 & 5.60 & $98.2 \%$ & Yes \\
\hline E & \multicolumn{6}{|c|}{ Pooled } \\
\hline $\mathrm{F}$ & \multicolumn{6}{|c|}{ Pooled } \\
\hline G & 0.504 & 2 & 0.252 & 7.90 & $99.4 \%$ & Yes \\
\hline $\mathrm{H}$ & \multicolumn{6}{|c|}{ Pooled } \\
\hline others & \multicolumn{6}{|c|}{ Pooled } \\
\hline Error & 0.415 & 13 & 0.032 & \multicolumn{3}{|c|}{$S_{\text {exp }}=0.18$} \\
\hline Total & 1.276 & 17 & & \multicolumn{3}{|c|}{ *Note: At least $95.0 \%$ confidence } \\
\hline
\end{tabular}

*SS: sum of squares; DOF: degree of freedom; Var.: variance; F: F-ratio; $\mathrm{S}_{\text {exp }}$ : experimental error. 


\subsection{Case Hardness}

To obtain optimum quality, analysis of variance (ANOVA) is an effective method to determine significant factors and optimum fabrication conditions. The contribution and confidence level of each factor constructed in Table 4 could identify the significant factor affecting the case hardness of carbonitrided self-drilling tapping screws. The contribution of a factor is the percentage of the sum of squares (SS), that is, the percentage of the factor variance to the total quality loss $[7,8]$. The effect of a factor may be pooled to error if its confidence level or contribution is relatively small. It is clear from the ANOVA table that the contribution of tempering temperature $(\mathrm{G})$ is $39.49 \%$ of the total variation, which is the highest contributor to the variability of the experimental results. The contribution of carbonitriding time (D) is $28.01 \%$, which is the second highest contribution. However, the other six factors are not significant for the $\mathrm{S} / \mathrm{N}$ ratio because their contributions are relatively small. With the pooling of errors from the non-significant factors (A, B, C, E, $\mathrm{F}$ and $\mathrm{H}$ ), the error estimation for the $\mathrm{S} / \mathrm{N}$ ratio is obtained [8] and then the confidence levels are $98.2 \%$ and $99.4 \%$, respectively, for carbonitriding time (D) and tempering temperature $(\mathrm{G})$. That is, both factors, particularly the tempering temperature, significantly affect the case hardness of carbonitrided self-drilling tapping screws, with more than a $95.0 \%$ confidence level

Figure 5 illustrates the factor response diagram and the level averages of eight factors with respect to the $\mathrm{S} / \mathrm{N}$ ratio. For each factor, the effect is the range of the level averages and the maximum level average is the optimum level [7, 8]. It is obviously revealed that, for the significant factors of carbonitriding time (D) and tempering temperature (G), Level 3 for carbonitriding time (60 min, D3) and Level 1 for tempering temperature $\left(300{ }^{\circ} \mathrm{C}, \mathrm{G} 1\right)$ are evidently the optimum levels, as shown in Figure 5. It is observed that their responses are almost linear with the carbonitriding time and tempering temperature.

The effects of the other six factors are relatively small. The optimum levels are Level 2 for the temperature of zone 3 $\left(880^{\circ} \mathrm{C}, \mathrm{A} 2\right)$, Level 3 for temperature of zone $5\left(870^{\circ} \mathrm{C}, \mathrm{B} 3\right)$, Level 1 for temperature of zone $6\left(800{ }^{\circ} \mathrm{C}, \mathrm{C} 1\right)$, Level 2 for carbon potential $(0.9 \%$, E2), Level 2 for flow rate of ammonia ( $0.5 \mathrm{l} / \mathrm{min}, \mathrm{F} 2)$, and Level 2 for tempering time (45 min, H2), respectively.

\subsection{Core Hardness}

For the core hardness of the carbonitrided self-drilling tapping screws, the ANOVA table of $\mathrm{S} / \mathrm{N}$ ratio is constructed in Table 5. It is evident from Table 5 that the highest contributors to the variability of the experimental results is the tempering temperature $(\mathrm{G}, 19.69 \%)$, the second is carbonitriding time (D, 19.59\%), the third is flow rate of ammonia (F, 17.60\%), the fourth is temperature of zone $5(\mathrm{~B}$, $15.17 \%$ ), and the fifth is carbon potential (E, 14.52\%). However, the temperature of zone 3 (A), temperature of zone $6(\mathrm{C})$ and tempering time $(\mathrm{H})$ are not significant factors because their contributions are relatively small. With the pooling of errors from the non-significant factors (A, C and $\mathrm{H})$, the confidence levels are $92.9 \%, 95.7 \%, 92.3 \%, 94.7 \%$, and $95.8 \%$, respectively, for the temperature of zone 5 (B), carbonitriding time (D), carbon potential (E), flow rate of ammonia (F) and tempering temperature (G). That is, the core hardness of the carbonitrided self-drilling tapping screws is significantly affected by the temperature of zone 5 , carbonitriding time, carbon potential, flow rate of ammonia and tempering temperature, with more than a $90.0 \%$ confidence level.

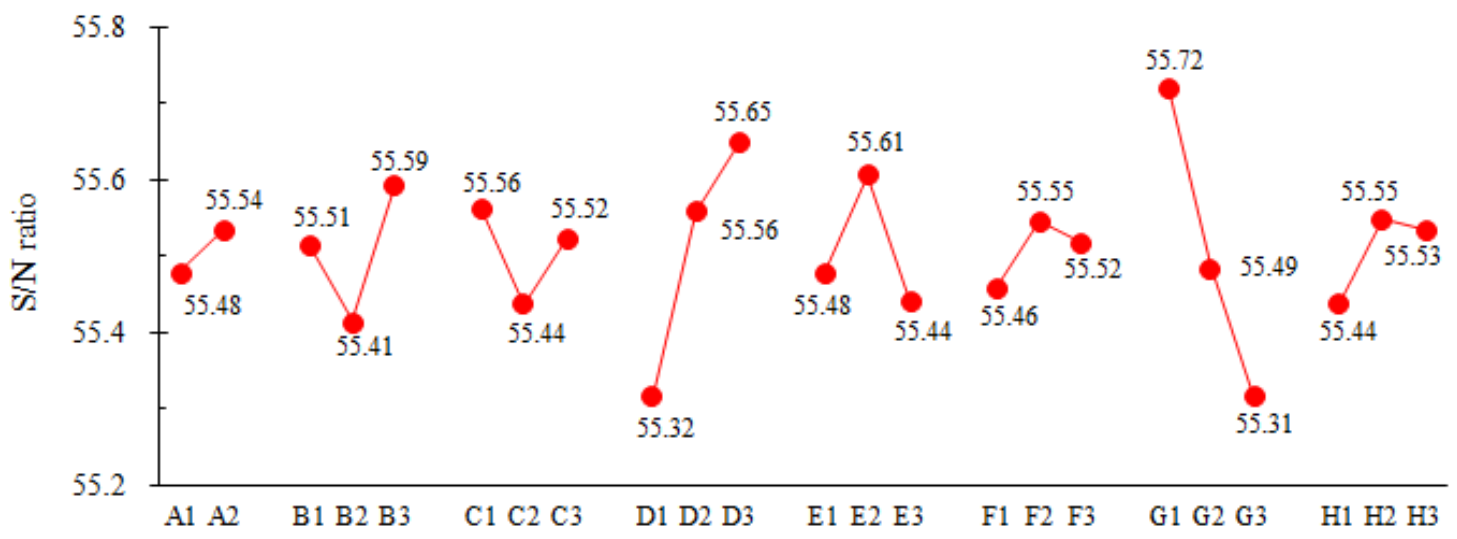

Figure 5. The factor response diagram for case hardness 
Table 5. Variance analysis table of signal-to-noise $(\mathrm{S} / \mathrm{N})$ ratio for core hardness.

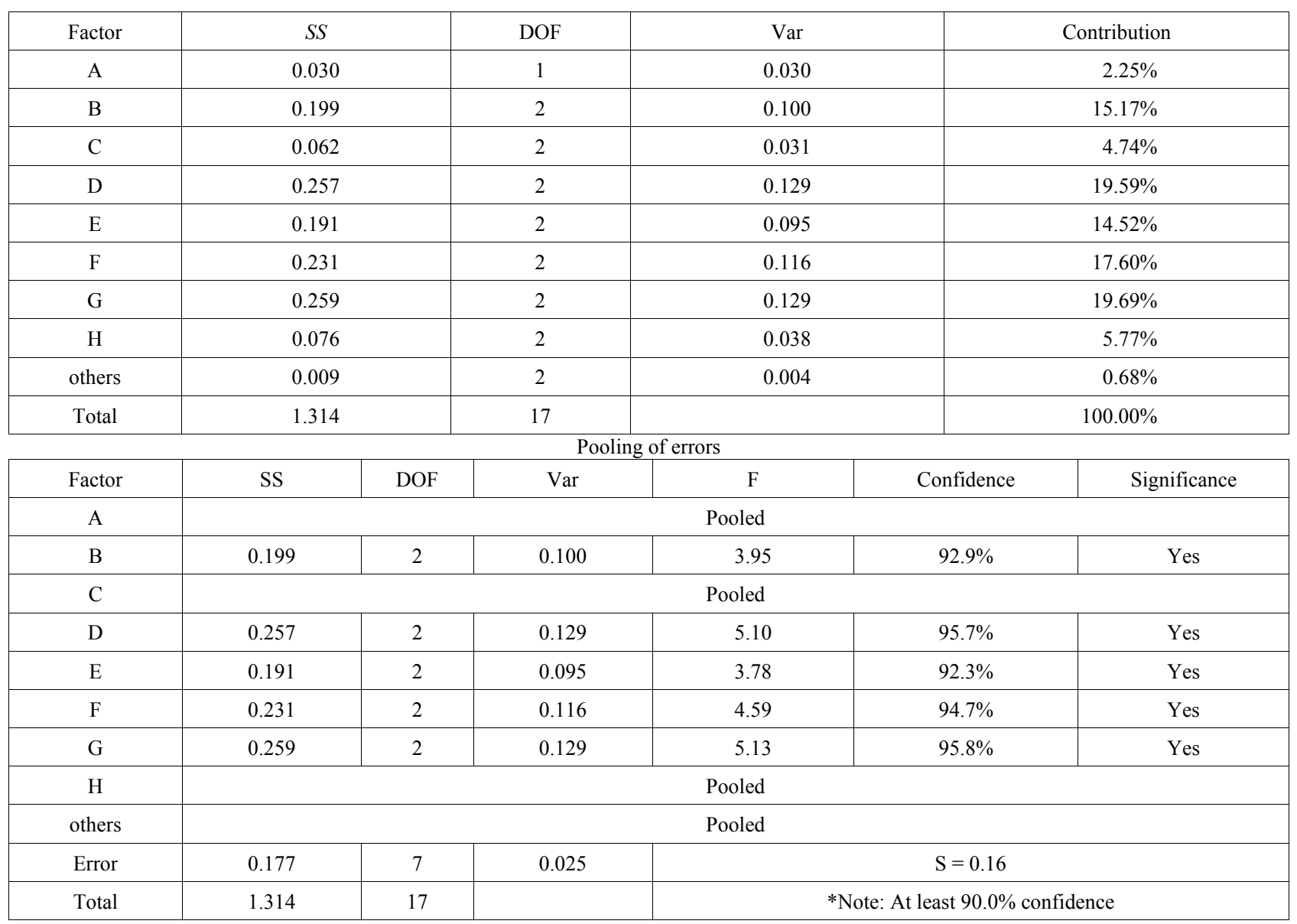

*SS: sum of squares; DOF: degree of freedom; Var.: variance; F: F-ratio; $S_{\text {exp }}$ experimental error.

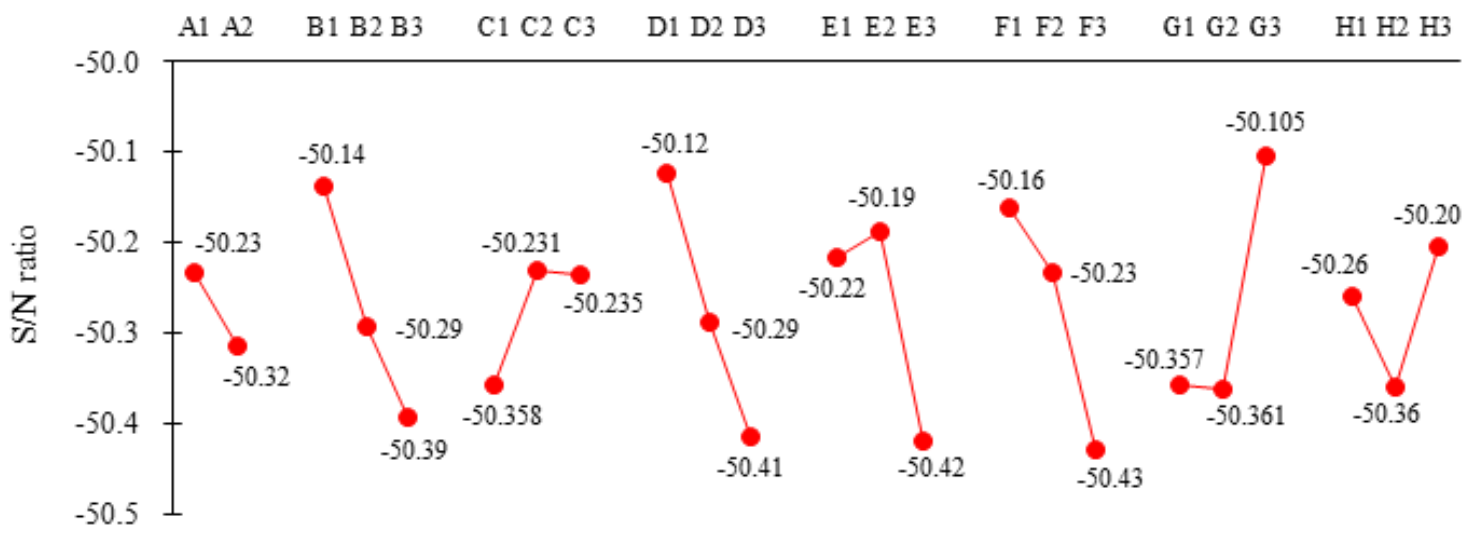

Figure 6. The factor response diagram for core hardness

The factor response diagram and the level averages of eight factors with respect to the $\mathrm{S} / \mathrm{N}$ ratio are illustrated in Figure 6. It is observed that the responses are not linear either with the temperature of zone $6(\mathrm{C})$, carbon potential $(\mathrm{E})$, tempering temperature $(\mathrm{G})$ or tempering time $(\mathrm{H})$; but are approximately linear with the temperature of zone 5 (B), carbonitriding time (D) and flow rate of ammonia (F). It is revealed that decreasing the temperature of zone 5 and carbonitriding time may lower the core hardness of the carbonitrided screws. Although the factors of the temperature of zone 5, carbon potential and flow rate of ammonia are significant factors in this study, they are not significant for case hardness, as shown in Figure 5.

For the five significant factors of the temperature of zone 5 (B), carbonitriding time (D), carbon potential (E), flow rate of ammonia $(\mathrm{F})$ and tempering temperature $(\mathrm{G})$, the optimum 
levels are Level 1 for the temperature of zone $5\left(840^{\circ} \mathrm{C}, \mathrm{B} 1\right)$, Level 1 for carbonitriding time (40 min, D1), Level 2 for carbon potential $(0.9 \%, \mathrm{E} 2)$, Level 1 for flow rate of ammonia $(0.6 \mathrm{l} / \mathrm{min}, \mathrm{F} 1)$ and Level 3 for tempering temperature $\left(340^{\circ} \mathrm{C}, \mathrm{G} 3\right)$, respectively, as shown in Figure 6 . The effects of the temperature of zone 3 (A), temperature of zone $6(\mathrm{C})$ and tempering time $(\mathrm{H})$ are relatively small. The optimum levels are Level 1 for the temperature of zone 3 $\left(870^{\circ} \mathrm{C}, \mathrm{A} 1\right)$, Level 2 for temperature of zone $6\left(820^{\circ} \mathrm{C}, \mathrm{C} 2\right)$ and Level 3 for the tempering time (50 min, H3), respectively.

With the optimum analysis for the quality characteristics of core hardness and case hardness, the optimum conditions are shown in Table 6 . Carbonitriding primarily provides a needed hard, wear-resistant case of screws. Case hardness is then the main quality characteristic. The factors of carbonitriding time (D) and tempering temperature $(\mathrm{G})$ are obviously significant for both the case hardness and core hardness. Therefore, the optimum levels are determined as Level 3 for the carbonitriding time (60 min, D3) and Level 1 for tempering temperature $\left(300^{\circ} \mathrm{C}, \mathrm{G} 1\right)$. The factors of the temperature of zone $5(\mathrm{~B})$, carbon potential (E) and flow rate of ammonia $(\mathrm{F})$ are not significant for case hardness, but are significant for core hardness. Thus, Level 3 for the temperature of zone $5\left(870^{\circ} \mathrm{C}, \mathrm{B} 3\right)$, Level 2 for carbon potential $(0.9 \%, \mathrm{E} 2)$ and Level 1 for flow rate of ammonia $(0.6 \mathrm{l} / \mathrm{min}, \mathrm{F} 1)$ are then chosen as the optimum levels. The factors of temperature of zone 3 (A), temperature of zone 6 (C) and tempering time $(\mathrm{H})$ are not significant either for case hardness or core hardness. Level 1 for the temperature of zone $3\left(870^{\circ} \mathrm{C}, \mathrm{A} 1\right)$, Level 1 for the temperature of zone 6 $\left(800^{\circ} \mathrm{C}, \mathrm{C} 1\right)$ and Level 1 for the tempering time (40 min, $\left.\mathrm{H} 1\right)$ are determined.

\subsection{Confirmatory Experiments}

In order to verify the predicted results, the self-drilling tapping screws are fabricated using the optimum levels: A1, B3, C1, D3, E2, F1, G1 and H1, as described in Table 6. Variation is the inability to perform a task consistently according to a specification [2]. Figure 7 shows the natural variations of the process (6 process standard deviations, $6 \mathrm{~S}$, Ostwald \& Munoz, 1997) of the eighteen tests together with the confirmatory experiment (optimum), including the given specification limit/spans, for the case hardness together with core hardness of carbonitrided screws.

Table 6. Optimum condition table for carbonitriding treatment.

\begin{tabular}{|c|c|c|c|}
\hline Factor & $\begin{array}{c}\text { Case } \\
\text { hardness }\end{array}$ & $\begin{array}{c}\text { Core } \\
\text { hardness }\end{array}$ & Optimum \\
\hline $\begin{array}{l}\text { A: Temperature of zone } 3 \\
\left({ }^{\circ} \mathrm{C}\right)\end{array}$ & A2 & $\mathrm{A} 1$ & A1 \\
\hline $\begin{array}{l}\text { B: Temperature of zone } 5 \\
\left({ }^{\circ} \mathrm{C}\right)\end{array}$ & B3 & $\mathrm{B} 1 *$ & B3 \\
\hline $\begin{array}{l}\text { C: Temperature of zone } 6 \\
\left({ }^{\circ} \mathrm{C}\right)\end{array}$ & $\mathrm{C} 1$ & $\mathrm{C} 2$ & $\mathrm{C} 1$ \\
\hline $\begin{array}{l}\text { D: Carbonitriding time } \\
(\mathrm{min})\end{array}$ & D3* & D1* & D3 \\
\hline E: Carbon potential (\%) & E2 & $\mathrm{E} 2 *$ & E2 \\
\hline $\begin{array}{l}\text { F: Flow rate of ammonia } \\
\qquad\left(\mathrm{NH}_{3}\right)(l / \mathrm{min})\end{array}$ & F2 & $\mathrm{F} 1^{*}$ & $\mathrm{~F} 1$ \\
\hline $\begin{array}{l}\text { G: Tempering temperature } \\
\left({ }^{\circ} \mathrm{C}\right)\end{array}$ & G1* & $\mathrm{G} 3 *$ & G1 \\
\hline $\mathrm{H}$ : Tempering time (min) & $\mathrm{H} 2$ & $\mathrm{H} 3$ & $\mathrm{H} 1$ \\
\hline
\end{tabular}

* Significant factor.

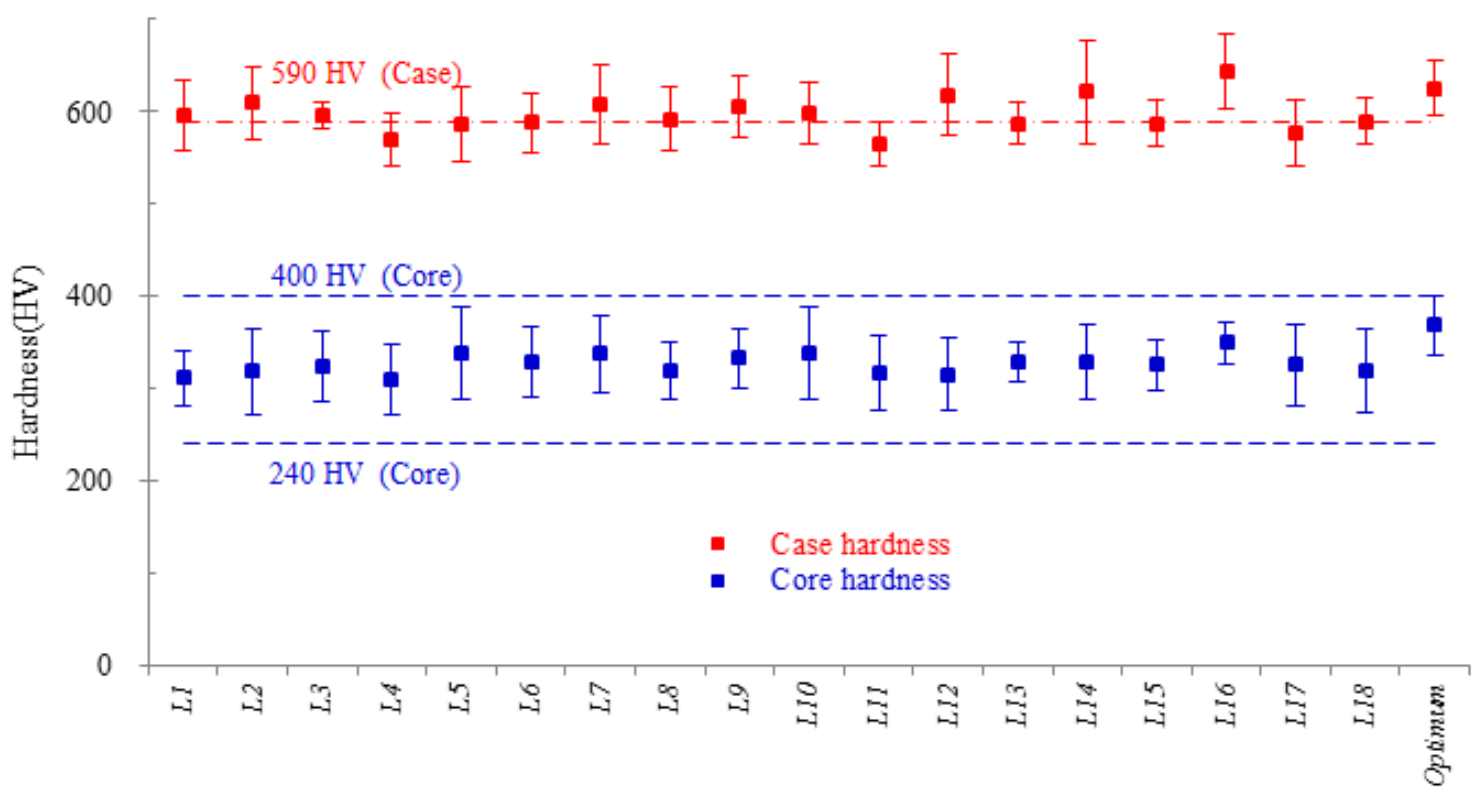

Figure 7. The natural variation of the process $(6 S)$ for the case and core hardness. 
Compared with the results of the eighteen tests, the optimum mean core hardness of $368.7 \mathrm{HV}$ is increased compared to the averaged value ( $326.3 \mathrm{HV}$ in Table 3 ) and the process natural variation $(6 S)$ is smaller than the given tolerance band, as shown in Figure 7. Although the core hardness of carbonitrided screws meets the requirement of specification for the eighteen tests, the quality characteristic of case hardness is not good enough, as shown in Figure 7, because the process natural variations $(6 S)$ of all tests (except test L16) are exceeding the lower specification limit for the case hardness. This means that the process is incapable of ensuring $99.73 \%$ of good carbonitrided screws [2].

The optimum mean case hardness of $625.5 \mathrm{HV}$ is larger than the averaged value $(596.8 \mathrm{HV}$ in Table 3 ) and even exceeding the assigned value of $590 \mathrm{HV}$; the natural variation of the process $(6 S)$ is smaller than test L16, as shown in Figure 7, and the process capability, $C_{p k}$, is 1.2 [2]. This means that the process is capable of ensuring $99.73 \%$ of good products in case hardness. Therefore, with the optimum conditions: A1, B3, C1, D3, E2, F1, G1 and H1, the carbonitriding treatment is capable of ensuring $99.73 \%$ of good self-drilling tapping screws.

\section{Materials and Methods}

In this study, the AISI 1016 steel wire coil is manufactured by China Steel Corporation, Kaohsiung, Taiwan. Its chemical composition is listed in Table 7. A series of carbonitriding treating experiment on AISI 1016 self-drilling tapping (M5.5 $\times 40 \mathrm{~mm}$ ) is conducted in MH900 continuous furnace (Hou Torng Engineering Co., Ltd., Taoyuan, Taiwan). The carbonitriding procedure is shown in Figure 8. The Taguchi method allows the changing of many factors at the same time in a systematic way. The orthogonal array table, $\mathrm{L}_{18}\left(2^{1} \times 3^{7}\right)$, is used as an experimental design for the factors [8], as listed in Table 2.

Table 7. Chemical composition of AISI 1016 low carbon steel wires (wt.\%).

\begin{tabular}{|c|c|c|c|c|c|}
\hline $\mathrm{C}$ & $\mathrm{Mn}$ & $\mathrm{P}$ & $\mathrm{S}$ & $\mathrm{Si}$ & $\mathrm{Al}$ \\
\hline 0.15 & 0.86 & 0.019 & 0.007 & 0.05 & 0.038 \\
\hline
\end{tabular}

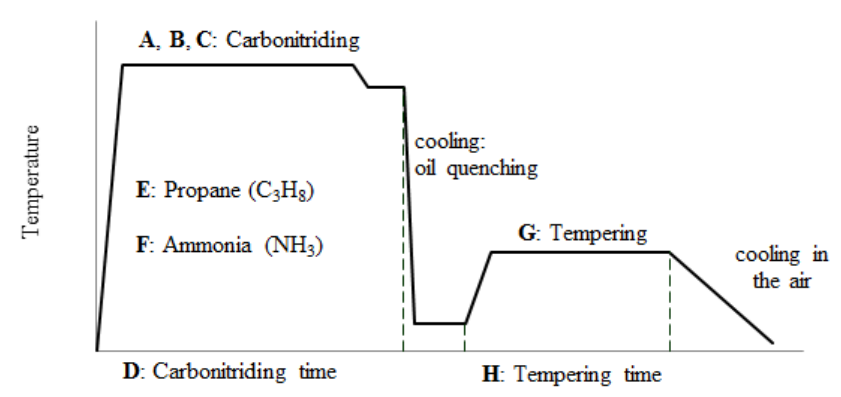

Figure 8. The carbonitriding procedure.

\section{Conclusions}

Carbonitriding is a modified form of gas carburizing by diffusing of both carbon and nitrogen into the surface layer enables the process to be carried out at lower temperatures and a shorter time than with carbon alone. In order to improve the qualities of AISI 1016 self-drilling tapping screws, a series of carbonitriding experiment was conducted in a continuous furnace. Various parameters affected the quality of carbonitriding such as quenching temperature, carbonitriding time, atmosphere composition (carbon potential and ammonia level), and tempering temperature. The effects of carbonitriding parameters affected the quality characteristics, such as case hardness and core hardness of self-drilling tapping screws were analyzed by Taguchi method. Carbonitriding primarily provided a needed hard, wear-resistant case of screws. Case hardness was then the main quality characteristic. It was experimentally revealed that the factors of carbonitriding time and tempering temperature were significant for both case hardness and core hardness; the factors of the temperature of zone 5, carbon potential and flow rate of ammonia were not significant for case hardness, but were significant for core hardness; however, the factors of temperatures of zone 3 and zone 6 and tempering time were not significant for either case hardness or core hardness. The optimum carbonitriding conditions were determined as $870^{\circ} \mathrm{C}$ carbonitriding temperature and $800^{\circ} \mathrm{C}$ quenching temperature for 60 minutes carbonitriding time with $0.9 \%$ carbon potential and $0.6 \mathrm{l} / \mathrm{min}$ flow rate of ammonia, followed by oil quenching and tempering at $300^{\circ} \mathrm{C}$ for 40 minutes. The optimum mean case hardness was $625.5 \mathrm{HV}$, and the optimum mean core hardness was $368.7 \mathrm{HV}$. Therefore, with the optimum conditions, the carbonitriding treatment was capable of producing good self-drilling tapping screws. The results might be used as a reference for fastener manufacturers.

\section{Acknowledgements}

The authors would like to acknowledge the Ministry of Science and Technology of the Republic of China (Taiwan, R.O.C.) for their support of this research under grant MOST 105-2632-E-244-001, and the support of Jau Yeou Ind. Co., Ltd., Kaohsiung, Taiwan, for providing the materials and apparatus to carry out the carbonitriding experimental work.

\section{REFERENCES}

[1] Stickels, C. A. (2011). Gas Carburizing. Heat Treating, vol. 4, ASM International: Materials Park, OH, USA.

[2] Ostwald, Phillip F., \& Munoz, Jairo (1997). Manufacturing Processes and Systems, John Wiley \& Sons, USA.

[3] Slycke, J., \& Ericsson, T. (1981). A study of reactions occurring during the carbonitriding process, Journal of Heat Treating, 2(1), 3-19. 
[4] Dossett, Jon (2011). Carbonitriding. Heat Treating, vol. 4, ASM International: Materials Park, OH, USA.

[5] Herring, Daniel H. (2011). Carbonitriding of Fasteners, Fastener Technology International, Vol. XXXIV, No. 3, 52-54.

[6] Winter, Karl-Michael (2013). Independently Controlled Carbon and Nitrogen Potential: A New Approach to Carbonitriding Process, Journal of Materials Engineering and Performance, 22(7), 1945-1956.
[7] Logothetis, N. (1992). Managing for Total Quality: From Deming to Taguchi and SPC, Prentice Hall International: London, UK.

[8] Lee, Huei-Huang (2008). Taguchi Methods: Principles and Practices of Quality Design, Gau Lih Book Co. Ltd., Taiwan.

[9] Yang, Chih-Cheng, \& Lin, Xuan-Yu (2016). The Forming Analysis of Two-stage Extrusion for 1010 Fastener, Journal of Mechanical Engineering and Automation, 6(3), 43-50. doi:10.5923/j.jmea.20160603.01 